\title{
Hepatitis C virus seroprevalence and prevalence of chronic infection in the adult population in Ireland: a study of residual sera, April 2014 to February 2016
}

P Garvey ${ }^{12}$, B 0’Grady ${ }^{3}$, G Franzoni ${ }^{3}, \mathrm{M} \mathrm{Bolger}^{3}$, K Irwin Crosby ${ }^{3}$, J Connell ${ }^{3}$, D Burke ${ }^{3}, \mathrm{C}$ De Gascun ${ }^{3}$, L Thornton ${ }^{1}$

1. Health Service Executive - Health Protection Surveillance Centre, Dublin, Ireland

2. European Programme for Intervention Epidemiology Training (EPIET), European Centre for Disease Prevention and Control (ECDC), Stockholm, Sweden

3. National Virus Reference Laboratory, University College Dublin, Dublin, Ireland

Correspondence: patricia.garvey@hse.ie

Garvey P, O'Grady B, Franzoni G, Bolger M, Irwin Crosby K, Connell J, Burke D, De Gascun C, Thornton L. Hepatitis C virus seroprevalence and prevalence of

chronic infection in the adult population in Ireland: a study of residual sera, April 2014 to February 2016. Euro Surveill. 2017;22(30):pii=30579. DOI: http://dx.doi.

org/10.2807/1560-7917.ES.2017.22.30.30579

Robust data on hepatitis C virus (HCV) population prevalence are essential to inform national HCV services. In 2016, we undertook a survey to estimate HCV prevalence among the adult population in Ireland. We used anonymised residual sera available at the National Virus Reference Laboratory. We selected a random sample comprising persons $\geq 18$ years with probability proportional to the general population age-sex distribution. Anti-HCV and HCV Ag were determined using the Architect anti-HCV and HCV Ag assays. Fifty-three of 3,795 specimens were seropositive (age-sex-area weighted seroprevalence $0.98 \% \quad(95 \%$ confidence interval (Cl): $0.73-1.3 \%)$ ). Thirty-three specimens were $\mathrm{HCV}$-antigen and antibody-positive (age-sex-area weighted prevalence of chronic infection $0.57 \%(95 \%$ $\mathrm{Cl}: 0.40-0.81 \%))$. The prevalence of chronic infection was higher in men $(0.91 \% ; 95 \% \mathrm{Cl}: 0.61-1.4 \%)$, in specimens from the east of the country $(1.4 \% ; 95 \% \mathrm{Cl}$ : 0.99-2.0\%), and among persons aged 30-39 years and $40-49$ years $(1.1 \%(95 \% \mathrm{Cl}: 0.59-2.0 \%)$ and $1.1 \%$ (95\% Cl: $0.64-1.9 \%)$ respectively). Ireland ranks at the lower end of the spectrum of prevalence of chronic HCV infection internationally. Men born between 1965 and 1984 from the east of the country have the highest rate of chronic HCV infection.

\section{Background}

Acute hepatitis C virus (HCV) infection is typically asymptomatic or associated with non-specific symptoms. Studies have indicated, however, that up to $80 \%$ of those infected will develop chronic infection, which can lead, over many decades, to cirrhosis, liver cancer and death $[1,2]$. Because of the asymptomatic nature of HCV infection, individuals can be infected for many years before diagnosis. Globally, the World Health Organization (WHO) has estimated that between 130 and 150 million people are HCV-infected [3,4], with the prevalence of $\mathrm{HCV}$ in some countries in central Asia (5.4\%), western Africa (5.3\%), central Africa (4.2\%), eastern Europe (3.3\%), and North Africa/Middle East (3.1\%) being higher than countries in North America $(1.0 \%)$ and western Europe (0.9\%) [5]. Within Europe, prevalence estimates of $0.4 \%$ to $5.2 \%$ have been reported, with countries in the north and west of Europe having lower estimates (0.9\%) than countries in the east of Europe $(3.3 \%)[5,6]$.

Historically, there was limited success in treating HCV, but in recent years, treatment with new direct-acting antivirals (DAAs) that possess high efficacy and improved safety profiles, has led many to suggest that the elimination of HCV is now possible [7]. Successful treatment not only benefits the individual by reducing his or her risk of cirrhosis and other liver-related outcomes, but also benefits the general population by reducing rates of onward transmission.

With the advent of highly potent and curative DAAs, many countries are now developing national strategies for population screening for HCV infection, and national HCV treatment programmes. Initiatives in Ireland include the formal establishment in 2015 by the Health Service Executive (HSE) of a National Hepatitis C Treatment Programme for known HCV-infected individuals [8]. Concurrently, a Guideline Development Group was convened by the HSE to develop national HCV screening guidelines to identify HCV-infected individuals who are currently unaware of their HCV status. For these approaches to be successful, the availability of robust data on population HCV seroprevalence is key, a fact recognised both by the Irish National Hepatitis C Strategy 2011-2014 [9], and likewise in December 2015, by the European Centre for Disease Prevention and Control (ECDC) [10]. 


\section{FIGURE 1}

Construction of hepatitis $\mathrm{C}$ virus study sampling frame, Ireland, 2014-2016
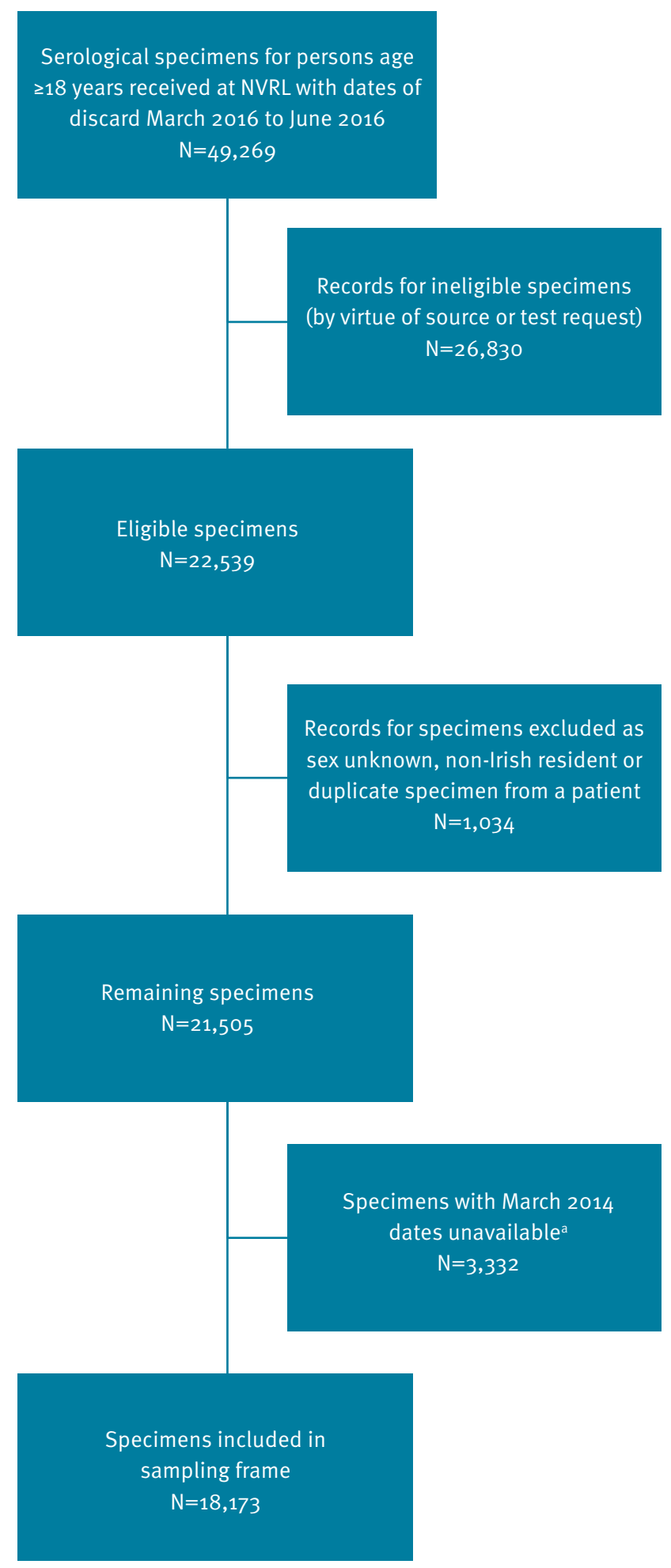

NVRL: National Virus Reference Laboratory

a Specimens collected in March 2014 and due for discard in March 2016 had been inadvertently discarded.
Ireland is believed to be a low-prevalence country for $\mathrm{HCV}$, and prior studies that measured the HCV seroprevalence in selected high-risk or localised populations, and in antenatal women [11-16], support this view; however, no national HCV prevalence studies in the general population have been conducted and the true burden of infection is unknown. We undertook a national cross-sectional study to estimate HCV seroprevalence and prevalence of HCV chronic infection among the adult population in Ireland.

\section{Methods}

\section{Study design and population}

The target population for our study was the adult population in Ireland. The sample was based on anonymised residual sera taken from persons aged 18 years or over submitted to the National Virus Reference Laboratory (NVRL). The NVRL provides a diagnostic and reference service for clinicians investigating viral infections throughout Ireland. Typically, around 200,000 blood specimens are received annually, equating to ca 150,000 serum specimens. They include specimens received for diagnostic purposes, antenatal screening, and pre-employment screening.

\section{Laboratory residual sera}

Specimens are classified as residual at the point where they are deemed no longer required for the purpose for which they were originally collected. It is NVRL policy to retain diagnostic samples for 4 months, antenatal samples for 24 months, needlestick source samples for 24 months, and occupational health screening specimens as requested. These time periods are intended to facilitate supplementary testing of the original sample should a clinical need arise. After the relevant time period has elapsed however, samples are discarded. For this study, residual specimens were available at the NVRL for a 3-month period for those specimens normally retained for 2 years (specimens collected April to June 2014), and for a 4-month period for those specimens normally retained for a 4-month period (specimens collected November 2015 to February 2016). Laboratory testing for the purposes of this study took place in July and August 2016.

\section{Sample size}

We estimated a sample size of 3,814 corresponding to an expected prevalence of chronic infection of $0.5 \%$, an absolute precision of $0.2 \%$, an alpha error of 0.05 , a design effect of 1 , and an eligible pool of ca 18,891 specimens.

\section{Sampling procedure}

The NVRL laboratory information management system was used to identify eligible specimens. Specimens marked on the system as being specifically retained for other reasons, e.g. sample from organ donors, were excluded. Antenatal specimens (where submitted for general antenatal screen at first 'booking') and preemployment screening specimens were all included in 


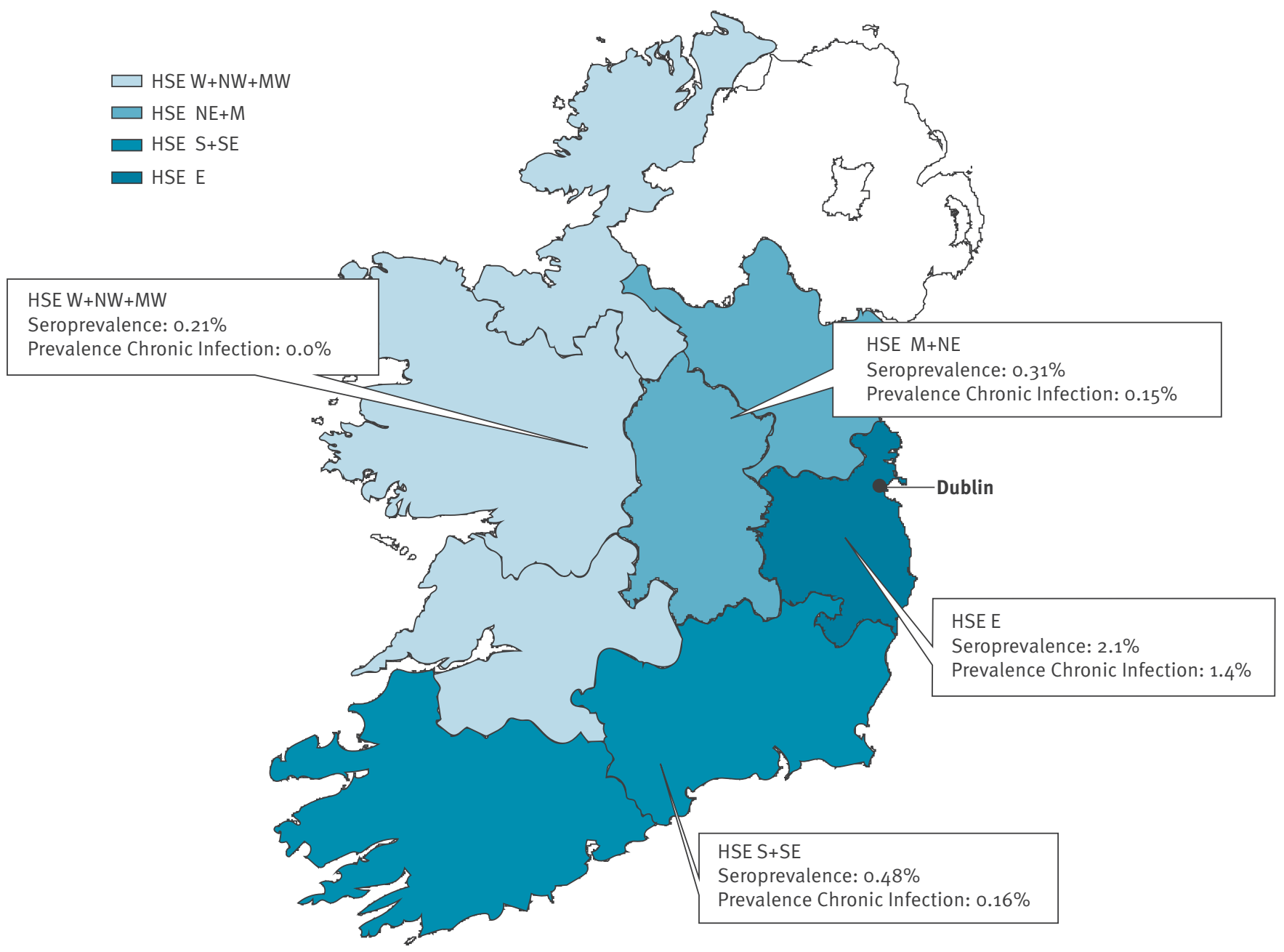

HSE: Health Service Executive; M: Midlands; MW: Mid West; NE: North East; NW: North West; S: South; SE: South East; W: West.

the sampling frame. To avoid the over-representation of persons who could have a HCV prevalence higher than expected in the general population, specimens collected from certain sources were considered ineligible for the study. These included: specimens sourced from drug treatment clinics or sexually transmitted infection (STI) clinics; specimens from hepatology or infectious disease services; specimens submitted specifically for a hepatitis, or STI screen; or specimens from asylum seekers (who are routinely screened for HCV in Ireland). Where possible, duplicate specimens from the same individual were identified by individually crosschecking the submission details for specimens from patients with the same initials and date of birth, and only one specimen per person was included in the sampling frame. We stratified the eligible specimens in the sampling frame by age group and sex. We selected a sample with probability proportional to the size of the age group and sex strata in the general population (as specimens submitted for diagnostic tests are likely to be biased at least by age). Within age-sex strata, we selected specimens using simple random sampling.

\section{Laboratory specimen analysis}

Where a selected specimen was found to have insufficient volume $(\langle 500 \mu \mathrm{L})$ for conducting the required laboratory tests, a replacement was selected randomly from the remaining specimens in the sample frame.

HCV antibody status was determined using the HCV Ab Architect Abbott HCV antibody test (Abbott Diagnostics, Wiesbaden, Germany), which detects only anti-HCV IgG, as the first line screen. Specimens exceeding the manufacturer's cut-off of 1.0 were investigated for the presence of HCV antigen using the HCV $\mathrm{Ag}$ Architect Abbott HCV antigen test. Samples reactive in the anti-HCV assay but negative for HCV Ag were subsequently tested using the Bio-Rad Monolisa antiHCV Plus vs 3.0 (Bio-Rad, Marnes-la-Coquette, France) to confirm the presence of anti-HCV. Specimens which generated discordant anti-HCV results were tested 
Demographic characteristics of the study sample $(n=3,795)$ and the general adult population in Ireland $(n=3,439,565)$, 2014-2016

\begin{tabular}{|c|c|c|c|c|c|}
\hline \multicolumn{2}{|c|}{ Characteristic } & \multicolumn{2}{|c|}{ Study sample } & \multicolumn{2}{|c|}{$\begin{array}{l}\text { General adult population in Ireland } \\
\qquad(\lambda=18 \text { years })^{\mathrm{a}}\end{array}$} \\
\hline & & $n$ & $\%$ & $\mathrm{n}$ & $\%$ \\
\hline \multirow{2}{*}{ Sex } & Female & 1,931 & $51 \%$ & $1,754,648$ & $51 \%$ \\
\hline & Male & 1,864 & $49 \%$ & $1,684,917$ & $49 \%$ \\
\hline \multirow{6}{*}{ Age group } & $18-29$ years & 856 & $23 \%$ & 772,275 & $22 \%$ \\
\hline & $30-39$ years & 838 & $22 \%$ & 758,206 & $22 \%$ \\
\hline & $40-49$ years & 705 & $19 \%$ & 635,997 & $18 \%$ \\
\hline & $50-59$ years & 574 & $15 \%$ & 518,908 & $15 \%$ \\
\hline & $60-69$ years & 436 & $11 \%$ & 392,424 & $11 \%$ \\
\hline & $70+$ years & 386 & $10 \%$ & 361,755 & $11 \%$ \\
\hline \multirow{4}{*}{ HSE area } & East & 2,288 & $60 \%$ & $1,236,870$ & $36 \%$ \\
\hline & Midlands and North East & 535 & $14 \%$ & 522,465 & $15 \%$ \\
\hline & South and South East & 556 & $15 \%$ & 869,316 & $25 \%$ \\
\hline & West, North West and Mid West & 416 & $11 \%$ & 810,914 & $24 \%$ \\
\hline \multirow{3}{*}{ Category } & Antenatal & 646 & $17 \%$ & NA & NA \\
\hline & Pre-employment & 131 & $3 \%$ & NA & NA \\
\hline & Other (e.g. diagnostic specimens) & 3,018 & $80 \%$ & NA & NA \\
\hline Total & & 3,795 & $100 \%$ & $3,439,565$ & $100 \%$ \\
\hline
\end{tabular}

a Census 2011, Central Statistics Office, Ireland

HSE: Health Service Executive; NA: not available.

using the Fujirebio INNO-LIA HCV score line immunoassay (Fujirebio Europe, Gent, Belgium) to determine the anti-HCV status of the sample.

\section{Definitions}

Specimens that were both HCV-antigen- and antibodypositive were considered to have been collected from an individual with chronic HCV infection. Specimens that were anti-HCV-positive but HCV-antigen-negative were considered indicative of resolved infection. Specimens that were $\mathrm{HCV}$-antigen-positive but that gave an indeterminate anti-HCV profile were considered as having been obtained from a subject with possible acute HCV infection. Specimens with indeterminate anti-HCV antibody status and that were HCV-antigen-negative were recorded as being of inconclusive HCV status.

\section{Information collected}

As the specimens used were derived from residual sera that had been submitted for a wide variety of reasons, the only information common to all specimens comprised basic demographic data such as age, sex, geographic area (Health Service Executive (HSE) areas are the public health administrative units in Ireland) and sample category (pre-employment screening, antenatal or other). These data were linked with the laboratory results in the study database.

\section{Statistical analysis}

We calculated the prevalence of HCV antibodies and chronic HCV infection and $95 \%$ confidence intervals (overall and by age, sex and area), weighted for undersampling in some age-sex strata and for geographical bias in sample selection. As a comparison group for antenatal studies previously conducted in Ireland, we also calculated the weighted prevalence of HCV antibodies in specimens from women aged 18-49 years.

Extrapolating from the prevalence in the sample, we estimated the number of persons seropositive or chronically $\mathrm{HCV}$ infected in the adult population in Ireland. Stata version 14.0 (Stata Corporation, Texas, US) statistical software was used for analyses

\section{Protection of human subjects and confidentiality}

The study received ethical approval from the Royal College of Physicians of Ireland (RCPI) Research Ethics Committee. All testing was anonymous and the identities of those whose specimens were tested were unknown to investigators. No contact was made with these individuals and they were unaware that they were included in the study. Before testing, eligible specimens were decanted and irrevocably anonymised using new specimen numbers. Only these new anonymised specimen numbers were recorded in the database.

\section{Results}

Construction of the study sampling frame NVRL database records for serological specimens received during the period of interest (due for discard 
Estimated hepatitis C virus (HCV) seroprevalence and prevalence of chronic HCV infection, and estimated number HCV seropositive and chronically infected, in the adult population in Ireland, by age and sex and Health Service Executive-area, Ireland, 2014-2016

\begin{tabular}{|c|c|c|c|c|c|c|c|c|c|c|c|}
\hline \multirow{2}{*}{\multicolumn{2}{|c|}{ Group }} & \multicolumn{3}{|c|}{$\begin{array}{l}\text { Seropositive in study sample } \\
\text { (chronic and resolved infections) }\end{array}$} & \multicolumn{2}{|c|}{$\begin{array}{l}\text { Seropositive adults in } \\
\text { general population }\end{array}$} & \multicolumn{3}{|c|}{$\begin{array}{l}\text { Chronically infected adults in } \\
\text { study sample }\end{array}$} & \multicolumn{2}{|c|}{$\begin{array}{l}\text { Chronically infected } \\
\text { adults in general } \\
\text { population }\end{array}$} \\
\hline & & Number & $\begin{array}{l}\text { Weighted } \\
\text { prevalence } \\
\text { (\%) }\end{array}$ & $95 \% \mathrm{Cl}$ & Number & $95 \% \mathrm{Cl}$ & Number & $\begin{array}{l}\text { Weighted } \\
\text { prevalence } \\
\text { (\%) }\end{array}$ & $95 \% \mathrm{Cl}$ & Number & $95 \% \mathrm{Cl}$ \\
\hline \multirow{2}{*}{ Sex } & Female & 14 & 0.42 & $0.25-0.71$ & 7,370 & $\begin{array}{l}4,387- \\
12,458\end{array}$ & 8 & 0.24 & $0.12-0.49$ & 4211 & $\begin{array}{l}2,106- \\
8,598\end{array}$ \\
\hline & Male & 39 & 1.57 & $1.12-2.19$ & 26,453 & $\begin{array}{l}18,871- \\
36,900\end{array}$ & 25 & 0.91 & $0.61-1.37$ & 15333 & $\begin{array}{c}10,278- \\
23,083\end{array}$ \\
\hline \multirow{6}{*}{ Age } & $18-29$ years & 1 & 0.07 & $0.01-0.47$ & 541 & $77-3,630$ & 0 & 0 & 0 & 0 & 0 \\
\hline & $30-39$ years & 20 & 1.94 & $1.21-3.10$ & 14,709 & $\begin{array}{l}9,174- \\
23,504\end{array}$ & 12 & 1.07 & $0.59-1.95$ & 8113 & $\begin{array}{l}4,473- \\
14,785\end{array}$ \\
\hline & $40-49$ years & 18 & 1.53 & $0.96-2.43$ & 9,731 & $\begin{array}{l}6,106- \\
15,455\end{array}$ & 13 & 1.11 & $0.64-1.91$ & 7060 & $\begin{array}{l}4,070- \\
12,148\end{array}$ \\
\hline & $50-59$ years & 6 & 0.83 & $0.33-2.09$ & 4,307 & $\begin{array}{l}1,712- \\
10,845 \\
\end{array}$ & 3 & 0.30 & $0.10-0.94$ & 1557 & $519-4,878$ \\
\hline & $60-69$ years & 5 & 0.69 & $0.29-1.66$ & 2,708 & $\begin{array}{c}1,138- \\
6,514 \\
\end{array}$ & 2 & 0.27 & $0.07-1.09$ & 1060 & $275-4,277$ \\
\hline & $70+$ years & 3 & 0.50 & $0.16-1.57$ & 1,809 & $\begin{array}{l}579- \\
5,680\end{array}$ & 3 & 0.50 & $0.16-1.57$ & 1809 & $579-5,680$ \\
\hline \multirow{4}{*}{ Area } & HSE E & 47 & 2.13 & $1.60-2.83$ & 26,345 & $\begin{array}{c}19,790- \\
35,003 \\
\end{array}$ & 31 & 1.41 & $0.99-2.01$ & 17440 & $\begin{array}{l}12,245^{-} \\
24,861 \\
\end{array}$ \\
\hline & HSE M+NE & 2 & 0.31 & $0.08-1.22$ & 1,620 & $418-6,374$ & 1 & 0.15 & $0.02-1.08$ & 784 & $104-5,643$ \\
\hline & HSE S+SE & 3 & 0.48 & $0.15-1.47$ & 4,173 & $\begin{array}{l}1,304^{-} \\
12,779\end{array}$ & 1 & 0.16 & $0.02-1.12$ & 1391 & $174-9,736$ \\
\hline & $\begin{array}{c}\mathrm{HSE} \\
W+N W+M W \\
\end{array}$ & 1 & 0.21 & $0.03-1.45$ & 1,703 & $\begin{aligned} 243^{-} \\
11,758 \\
\end{aligned}$ & 0 & 0 & 0 & 0 & 0 \\
\hline All & $\begin{array}{c}\text { Population } \\
18+\text { years }\end{array}$ & 53 & 0.98 & $0.73-1.31$ & 33,708 & $\begin{array}{c}25,109- \\
45,058 \\
\end{array}$ & 33 & 0.57 & $0.40-0.81$ & 19,606 & $\begin{array}{l}13,758- \\
27,860 \\
\end{array}$ \\
\hline
\end{tabular}

Cl: confidence interval; E: East; HCV: hepatitis C virus; HSE: Health Service Executive; M: Midlands; MW: Mid West; NE: North East; NW: North West; S: South; SE: South East; W: West.

March to June 2016) were reviewed to see if they met the study inclusion and exclusion criteria. Excluding records for specimens flagged for specific retention for other reasons, and those from persons less than 18 years of age, records were available for 49,269 specimens.

10,382 records were identified for antenatal screening specimens and 615 records for pre-employment screen specimens. After exclusions were applied to the 38,372 records for diagnostic specimens, 11,542 records remained, which, when combined with the antenatal and pre-employment screen records, totalled 22,539 records (Figure 1 ).

A further 1,034 records were excluded for the following reasons: no sex was recorded, the patient had a nonIrish residential address, or more than one specimen had come from the same individual. At this point, we also became aware that specimens collected in March 2014 and due for discard in March 2016 had already been discarded, leaving 18,173 specimens in the final sampling frame (Figure 1).
Antenatal specimens made up 7,600 (42\%), preemployment screen specimens 499 (3\%) and the remaining diagnostic specimens $10,074(55 \%)$ of this sampling frame.

\section{Demographic and specimen characteristics of study sample}

From a sampling frame of 18,173 specimens, a study sample of 3,814 specimens was selected. After including replacements for specimens of insufficient volume (where possible), the final sample comprised 3,795 specimens ( $99.5 \%$ of the desired number), with minimal under-sampling in three age-sex strata. Reflecting the referral bias we might expect in a national service based in the east of the country, the study sample contained a higher proportion of specimens from individuals resident in HSE-East $(60 \%)$, which includes the greater Dublin area, compared with the general adult population in Ireland (36\%) (Table 1). This geographical bias was accounted for in the weighted analysis presented below. 


\section{Laboratory findings and interpretation}

Laboratory findings were consistent with 33 specimens having been collected from patients with chronic HCV infection, 20 from patients with resolved HCV infection, and one from a patient with possible acute infection; 3,737 specimens tested negative for anti-HCV. Four specimens yielded inconclusive anti-HCV results: in the ordinary course of events, the NVRL laboratory testing algorithms would have indicated that further specimens should be requested from these individuals, but this was not possible in this situation. Thus, in this study sample, the HCV chronicity rate was calculated as $62 \%$ (33 chronic out of 53 chronic plus resolved infections).

\section{Seroprevalence}

Overall, the 53 specimens confirmed as seropositive (Table 2) corresponded to a weighted seroprevalence of $0.98 \%(95 \% \mathrm{Cl}: 0.73-1.3 \%)$. Based on these findings, we estimate that 33,708 people in the adult population in Ireland have had previous exposure to HCV.

Seroprevalence was significantly higher in men (1.6\%; 95\% Cl: $1.1-2.2 \%)$ than in women (0.42\%; $95 \% \mathrm{Cl}$ : $0.25-0.71 \%)$, and in specimens from HSE-East $(2.1 \%$; $95 \% \mathrm{Cl}: 1.6-2.8 \%)$ than in specimens from other areas (Table 2 and Figure 2). Although not statistically significant, there was also a higher seroprevalence among specimens from people aged $30-39$ years (1.9\%; 95\% $\mathrm{Cl}: 1.2-3.1 \%)$ and $40-49$ years $(1.5 \% ; 95 \% \mathrm{Cl}: 0.96-$ $2.4 \%)$ than in other age groups.

We calculated the weighted seroprevalence among women aged between 18 and 49 years old to be $0.40 \%$ (95\% Cl: $0.20-0.76 \%$ ).

\section{Prevalence of chronic infection}

The 33 specimens with serology consistent with chronic $\mathrm{HCV}$ infection corresponded to a weighted prevalence of chronic infection of $0.57 \%$ ( $95 \% \mathrm{Cl}: 0.40-0.81 \%)$. Based on this, we estimate that 19,606 persons in the adult population in Ireland have chronic HCV infection (Table 2).

The prevalence of chronic HCV infection was again significantly higher in men (0.91\%; 95\% Cl: $0.61-1.4 \%)$ than in women (0.24\%; 95\% Cl: $0.12-0.49 \%$ ), and higher but not significantly so in specimens from HSE-East (1.4\%; 95\% Cl: 0.99-2.0\%) compared with specimens from other areas (Table 2 and Figure 2). There was also a higher prevalence of chronic infection among persons aged 30-39 years and 40-49 years (Table 2), although again, this was not statistically significant. No chronic infections were noted in the 18-29 years age group for either sex, and overall, the highest prevalence of chronic infection was in men aged 40-49 years in HSE-East (5.2\%; 95\% Cl: 2.8-9.3\%) and in men aged $30-39$ years in HSE-East $(3.5 \%$; $95 \% \mathrm{Cl}$ : $1.8-6.9 \%)$.

\section{Discussion}

This is the first HCV population prevalence study to have been undertaken in Ireland. Compared with published studies, the estimated prevalence of $0.57 \%$ for chronic HCV infection suggests that Ireland ranks at the lower end of the spectrum in terms of HCV prevalence internationally $[5,6]$. Our findings furthermore suggest that based on age, sex, and geographical area, men born between 1965 and 1984 from the east of the country have the highest rate of chronic HCV infection in Ireland.

Our findings are broadly in line with those of a previous study that calculated a chronic HCV infection rate based on the number of new HCV laboratory diagnoses between 1989 and 2004, combined with Irish HCV notification data for 2004-2009 [17]. After applying a number of assumptions in relation to reporting bias, under-diagnoses, establishment of chronic infection, and case fatality, the authors estimated a population prevalence of chronic HCV infection of between 0.5 and $1.2 \%$ in 2011.

Our findings for women aged 18-49 years are also in line with estimates from HCV antibody prevalence studies conducted in two Dublin hospitals on antenatal women in 2007 [16] and 2007-2008 [15], which estimated seroprevalences of $0.7 \%$ with $57 \%$ HCV RNA positive [16], and $0.9 \%$ with HCV RNA positivity of $64 \%$ [15], respectively. The slightly lower weighted seroprevalence among women aged between 18 and 49 years in our study is perhaps not surprising given that it represents a wider geographical area, with the earlier published studies having been performed in settings largely serving women from the greater Dublin area.

$\mathrm{HCV}$ is a notifiable disease in Ireland both by clinicians and laboratories. Our findings are also consistent with recent Irish HCV notification data in terms of age, sex and geographical area; $69 \%$ of Irish HCV notifications in 2014 were reported from HSE-East, with injecting drug use reported as the most common risk factor at $80 \%$ [18]. It seems plausible given the age-sex-geographical distribution of our data, that our findings could also be substantially influenced by the occurrence of $\mathrm{HCV}$ infection in people who currently inject drugs, or have done so in the past.

Since the introduction of screening of donated blood for HCV in the early 1990s, HCV transmission through blood and blood products is rare. Prior to that, however, around 1,700 cases of $\mathrm{HCV}$ infection were acquired through blood and blood products in Ireland; their disease history is being documented in the National Hepatitis C Database $[19,20]$. Some of these have been successfully treated with antiviral therapy; however, the group remains an important sub-group of the seropositive population in Ireland, and may explain some of the seropositive specimens we identified in older adults. 
In a review of the natural history of HCV infection, Seeff and colleagues described chronic infection rates of up to $80 \%$ in studies of HCV-infected adults, with lower rates of ca $50 \%$ in infected children or young women [1]. Our overall estimated chronicity rate of $62 \%$ is at the lower end of this range, but the study was not designed to reflect the natural history of HCV infection in Ireland or to take into account factors such as antiviral treatment.

Compared with previous studies in Ireland, based on high-risk, localised or antenatal populations [11-16], this study has the advantage of being a national survey representative of the general adult population. Large in size, it provides good precision in our overall estimate and in selected subgroups. As it used specimens already collected for other diagnostic and screening investigations, it was relatively inexpensive to perform, and provided a population estimate in a short time frame.

The main limitation of our study is potential bias because individuals whose specimens are submitted to NVRL for testing are not likely to be completely representative of the general adult population. To minimise bias by age group and sex, we stratified the sampling frame before sampling, and sampled with probability proportional to the size of the strata in the general population. In addition, to adjust for geographical bias in sample selection and for under-sampling in three age-sex strata, we weighted for HSE area, age group and sex in the analysis.

Attempts were made to minimise potential bias by excluding certain categories of residual specimens from persons who would be expected to have a higher risk of being HCV-seropositive (e.g. specimens from STI clinics, drug treatment services, or those that were submitted specifically for HCV testing). The intent was to avoid the over-representation of persons in risk groups that might arise from inclusion of specimens from these sources. Due to the large number of specimens excluded on such grounds however, it could be argued that we have selected a sample biased towards lowrisk specimens, and therefore the estimate obtained should be considered the minimum.

Compared with other study designs $[15,21,22]$, we had limited opportunity to look at risk factors other than age, sex and geographical area, as the sample was drawn from residual sera. The anonymous nature of the survey also precludes us from knowing what proportion of these individuals are already aware of their HCV status, what proportion of resolved infections were consequent to antiviral treatment, and also prevents referral of patients with positive specimens to care pathways.

Notwithstanding these limitations, these data are the best estimates to date in Ireland of HCV seroprevalence in the general population and we believe they will serve to: (i) provide more accurate information for the public on their likely risk of infection; (ii) inform health service planning regarding future screening programmes, future burden of HCV-associated disease and demand for antiviral treatment in Ireland; and (iii) provide a benchmark for evaluating the effectiveness of primary and secondary HCV prevention programmes. Owing to its simplicity, low cost, and rapidity, we would also recommend this study design as a model for sero-epidemiological studies for other diseases in Ireland, or for HCV sero-epidemiological studies elsewhere in Europe.

\section{Acknowledgements}

We are grateful to Niamh Murphy for advice on study design and to Fiona Cloak for assistance with map creation. Patricia Garvey is also grateful for advice received from Dr. Kostas Danis, EPIET Scientific Coordinator based at Santé publique France.

\section{Conflict of interest}

None declared.

\section{Authors' contributions}

Patricia Garvey: Contributed to study concept and design, developed the research protocol, contributed to laboratory protocol and laboratory specimen selection, performed the statistical analysis and interpretation of statistical findings, and drafted the manuscript.

Brian O'Grady: Contributed to laboratory protocol and laboratory specimen selection, managed laboratory data and read and approved the manuscript for submission.

Geraldine Franzoni, Maeve Bolger and Katie Irwin Crosby: Conducted laboratory testing and read and approved the manuscript for submission.

Deirdre Burke: Contributed to laboratory protocol, supervised laboratory testing and read and approved the manuscript for submission.

Jeff Connell and Cillian De Gascun: Contributed to study concept and design, research protocol and laboratory protocol. Had overall responsibility for laboratory aspects of the study, including interpretation of laboratory findings, and read and approved the manuscript for submission.

Lelia Thornton: Contributed to study concept and design, research protocol and interpretation of statistical findings. Responsible for overall study supervision and read and approved the manuscript for submission.

\section{References}

1. Seeff LB. The history of the "natural history" of hepatitis C (1968-2009).Liver Int. 2009;29(Suppl 1):89-99. DOI: 10.1111/j.1478-3231.2008.01927.x PMID: 19207971

2. Westbrook RH, Dusheiko G. Natural history of hepatitis C.J Hepatol. 2014;61(1) Suppl;S58-68. DOI: 10.1016/j. jhep.2014.07.012 PMID: 25443346

3. World Health Organization (WHO). Hepatitis C Fact sheet. Geneva: WHO. [Accessed 24 Oct 2016]. Available from: http:// www.who.int/mediacentre/factsheets/fs164/en/ 
4. Mohd Hanafiah K, Groeger J, Flaxman AD, Wiersma ST. Global epidemiology of hepatitis $C$ virus infection: new estimates of age-specific antibody to HCV seroprevalence.Hepatology. 2013;57(4):1333-42. DOI: 10.1002/hep.26141 PMID: 23172780

5. Gower E, Estes C, Blach S, Razavi-Shearer K, Razavi H. Global epidemiology and genotype distribution of the hepatitis C virus infection.J Hepatol. 2014;61(1) Suppl;S45-57. DOI: 10.1016/j.jhep.2014.07.027 PMID: 25086286

6. European Centre for Disease Prevention and Control (ECDC). Technical Report. Hepatitis B and C in the EU neighbourhood: prevalence, burden of disease and screening policies. Stockholm: ECDC; 2010. Available from: http://ecdc.europa.eu/ en/publications/Publications/TER_100914_Hep_B_C\%20_EU_ neighbourhood.pdf

7. The Lancet. Hepatitis C: only a step away from elimination?Lancet. 2015;385(9973):1045. DOI: 10.1016/S01406736(15)60584-0 PMID: 25797543

8. Health Service Executive (HSE). National Hepatitis C Treatment Programme. Dublin: HSE. [Accessed 24 Oct 2016]. Available from: http://www.hse.ie/eng/about/Who/primarycare/ hepcprogramme\%20.html

9. Health Service Executive (HSE). 2012. National Hepatitis C Strategy 2011-2014. Dublin: HSE. [Accessed 24 Oct 2016]. Available from: http://www.lenus.ie/hse/ bitstream/10147/243033/1/HepCstrategy.pdf

10. European Centre for Disease Prevention and Control (ECDC). Tender for the development of a seroprevalence survey for hepatitis C in EU/EEA countries. Stockholm: ECDC; 12 Dec 2015. Available from: http://ecdc.europa.eu/en/aboutus/calls/_ layouts/forms/Call_DispForm.aspx?ID $=751 \&$ List $=02511 \mathrm{~b} 7 \bar{b}$ 3a16-4C4b-9304-54cfco8a1647\#sthash.K8C1sC33.dpuf

11. Grogan L, Tiernan M, Geogeghan N, Smyth B, Keenan E. Bloodborne virus infections among drug users in Ireland: a retrospective cross-sectional survey of screening, prevalence, incidence and hepatitis B immunisation uptake.Ir J Med Sci. 2005;174(2):14-20. DOI: 10.1007/BF03169123 PMID: 16094907

12. Smyth BP, Barry J, Keenan E. Irish injecting drug users and hepatitis C: the importance of the social context of injecting.Int J Epidemiol. 2005;34(1):166-72. DOI: 10.1093/ije/dyh347 PMID: 15513970

13. Allwright S, Bradley F, Long J, Barry J, Thornton L, Parry JV. Prevalence of antibodies to hepatitis B, hepatitis C, and HIV and risk factors in Irish prisoners: results of a national cross sectional survey.BMJ. 2000;321(7253):78-82. DOI: 10.1136/ bmj.321.7253.78 PMID: 10884256

14. O'Connell S, Lillis D, Cotter A, O'Dea S, Tuite H, Fleming C, et al. Opt-Out Panel Testing for HIV, Hepatitis B and Hepatitis C in an Urban Emergency Department: A Pilot Study. PLoS One. 2016;11(3):e0150546. DOI: 10.1371/journal.pone.0150546 PMID: 26967517

15. Lambert J, Jackson V, Coulter-Smith S, Brennan M, Geary M, Kelleher TB, et al. Universal antenatal screening for hepatitis C. Ir Med J. 2013;106(5):136-9.PMID: 23914572

16. Martyn F, Phelan O, O'Connell M. Hepatitis C: is there a case for universal screening in pregnancy? Ir Med J. 2011;104(5):1446.PMID: 21736090

17. Thornton L, Murphy N, Jones L, Connell J, Dooley S, Gavin S, et al. Determination of the burden of hepatitis $C$ virus infection in Ireland. Epidemiol Infect. 2012;140(8):1461-8. DOI: 10.1017| So950268811001920 PMID: 21923968

18. Health Protection Surveillance Centre (HPSC). Annual Epidemiological Report 2014. Dublin: HPSC; 2014. Available from: http://www.hpsc.ie/AboutHPSC/AnnualReports/ File,15505,en.pdf

19. Health Protection Surveillance Centre (HPSC). National Hepatitis C Database for infection acquired through blood and blood products: Baseline Report. Dublin: HPSC; 2007. Available from: http://www.hpsc.ie/a-z/hepatitis/hepatitisc/ hepatitiscdatabase/baselineandfollow-upreports/File,2537,en. pdf

20. Health Protection Surveillance Centre (HPSC). National Hepatitis C Database for infection acquired through blood and blood products: 2015 Report. Dublin: HPSC; 2015. Available from: http://www.hpsc.ie/a-z/hepatitis/ hepatitisc/hepatitiscdatabase/baselineandfollow-upreports/ File,15238,en.pdf

21. Vriend HJ, Op de Coul EL, van de Laar TJ, Urbanus AT, van der Klis FR, Boot HJ. Hepatitis C virus seroprevalence in the Netherlands.Eur J Public Health. 2012;22(6):819-21. DOI: 10.1093/eurpub/cks013 PMID: 22461704

22. Vriend HJ, Van Veen MG, Prins M, Urbanus AT, Boot HJ, Op De Coul EL. Hepatitis C virus prevalence in The Netherlands: migrants account for most infections. Epidemiol Infect. 2013;141(6):1310-7. DOI: 10.1017/So950268812001884 PMID: 22963908

\section{License and copyright}

This is an open-access article distributed under the terms of the Creative Commons Attribution (CC BY 4.0) Licence. You may share and adapt the material, but must give appropriate credit to the source, provide a link to the licence, and indicate if changes were made.

This article is copyright of the authors, 2017. 